\title{
Response to the correspondence "Preservation of vaginal elasticity is essential for avoiding mesh complications after prolapse surgery" by P Petros and P Richardson
}

\author{
G. Gutvirtz ${ }^{1}$ A. Y. Weintraub ${ }^{1}$
}

Received: 23 October 2017 / Accepted: 23 October 2017 / Published online: 6 November 2017

(C) Springer International Publishing AG, part of Springer Nature 2017

Dear Sir,

We congratulate P. Petros and P. Richardson for their important contribution to the mesh debate, in particular, their comment about massive urine loss immediately after mesh surgery [1].

The complications of mesh surgery occupied an important part of the discussions at the 2016 meeting of the International Society of Pelviperineology (ISPP) held in Israel in 2016 [2].

Most worrying were the reports from ISPP surgeons of patients suffering from the sudden onset of massive urine loss immediately after surgery using mesh sheets. We believe that this condition is similar to a major diagnostic and treatment breakthrough recently reported from the African fistula experience, that massive scarring in the vagina is the prime cause of post-vesicovaginal fistula repair incontinence, and that it can be repaired by restoring vaginal elasticity $[3,4]$. Some 2-3 million women suffer from Obstetric Fistula in Africa. Despite an up to 95\% cure rate of the fistula itself, up to $55 \%$ of such women complain of massive urinary incontinence [3]. It was hypothesized that the problem was excessive vaginal fibrosis in the vagina which prevented the action of the opposite striated muscle vector forces [4]. The initial results were a dramatic rise in dryness on insertion of a Singapore Flap skin graft during surgery. This works by restoring elasticity in the vagina $[4,5]$.

We believe that de novo massive urine loss after mesh sheet surgery has the same pathogenesis as obstetric fistula

G. Gutvirtz

Giltzik@gmail.com

1 Department of Obstetrics and Gynecology, Soroka

University Medical Center, Beersheba, Israel and that the methodology for cure described for post-fistula repair incontinence, i.e. restoring the elasticity of the bladder neck area of the vagina $[4,5]$ needs to be followed as part of any surgery for mesh removal. This is the only way to restore the elasticity required in this critical area for independent function of the opposite vector forces. Because the pubourethral ligaments are necessarily severed during urethrolysis, a midurethral sling should also be applied [5].

Compliance with ethical standards

Conflict of interest The authors declare that they have no conflict of interest.

Ethical approval This article does not contain any studies with human participants or animals performed by any of the authors.

Informed consent For this type of study formal consent is not required.

\section{References}

1. Petros P, Richardson P (2017) Preservation of vaginal elasticity is essential for avoiding mesh complications after prolapse surgery. Tech Coloproctol 21:589. https://doi.org/10.1007/ s10151-017-1650-8

2. Weintraub AY, Ginat S (2017) To dream is simply to be pragmatic. Pelviperineology $36: 34$

3. Browning A (2017) Towards a solution for obstetric fistula problems. Pelviperineology $36: 2$

4. Petros P, Williams G, Browning A (2015) Post vesico-vaginal fistula repair incontinence-a new hypotheses and classification potentially guide prevention and cure. Pelviperineology 34:48-50

5. Browning A, Williams G, Petros P (2017) Prevention and cure of post vesico-vaginal fistula repair incontinence by insertion of skin graft in the bladder neck area of vagina. Update on hypothesis and interim report. Pelviperineology 36:9-11 